\title{
The Characteristics Of Human Bone-Derived Cells (HBDCS) during osteogenesis in vitro
}

\author{
Edyta Wrobel $^{1 *}$, Joanna Leszczynska ${ }^{1}$ and Edyta Brzoska ${ }^{2}$
}

\author{
* Correspondence: \\ edyta.wrobel@wum.edu.pl \\ ${ }^{1}$ Department of Biophysics and \\ Human Physiology, Faculty of \\ Health Sciences, Medical University \\ of Warsaw, ul. Chalubinskiego 5, \\ 02-004, Warsaw, Poland \\ Full list of author information is \\ available at the end of the article
}

\begin{abstract}
Background: The primary human bone-derived cell culture technique is used as a model to study human osteogenesis. Compared to cell line cultures, primary osteoprogenitor and osteoblast cultures provide more complex information about osteogenesis, bone remodeling and regeneration than cell line cultures.

Methods: In this study, we isolated human bone-derived cells (HBDCs) and promoted their differentiation into osteoblasts. The following parameters were evaluated: cell number and viability, total protein expression, alkaline phosphatase activity, collagenous matrix production and osteogenic genes expression, i.e., gene coding for type I collagen and alkaline phosphatase.

Results: It was proved the results show that HBDCs intensively proliferate during the first 7 days of culture followed by differentiation accompanied by an increase in alkaline phosphatase activity. Moreover, it was observed that during the differentiation of HBDCs, the expression of integrin $\beta 1$ increased.

Conclusions: The process was also accompanied by changes in cell shape and rearrangement of the actin cytoskeleton and focal contacts containing FAK and the integrin $\beta 1$ subunit. We suggest that the $\beta 1$ integrin subunit may be a suitable new target in studies of the differentiation of primary human osteoblasts in culture.

Keywords: Human bone-derived cells, Integrins, Osteoblast differentiation, Osteogenesis in vitro, Osteogenic markers, Primary osteoblasts
\end{abstract}

\section{Background}

Bone is a highly organized structure of calcified connective tissue formed during osteoprogenitor proliferation and differentiation into mature osteoblasts. Osteoblasts (boneforming cells) are identified on the basis of morphology - their cuboidal appearance - and their association with bone matrix.

Osteoblast maturation consists of three main phases: proliferation, extracellular matrix (ECM) synthesis, and mineralization [1]. Osteoblast differentiation from their undifferentiated to functional state is accompanied by changes in cell morphology and in the expression of adhesion molecules, ECM proteins (collagen type I; COLI) and specific osteogenic markers, i.e., alkaline phosphatase (ALP), osteocalcin (OC), osteopontin (OP), osteonectin $(\mathrm{ON})$ and bone sialoprotein (BSP). ALP is considered a relative early marker of osteoblast differentiation [2]. The subsequent reconstruction of a collagenous matrix occurs in the course of procollagen I mRNA decrease [3] and OC expression increase, a late marker of differentiated osteoblasts [1].

(C) The Author(s). 2016 Open Access This article is distributed under the terms of the Creative Commons Attribution 4.0 International License (http://creativecommons.org/licenses/by/4.0/), which permits unrestricted use, distribution, and reproduction in any medium, provided you give appropriate credit to the original author(s) and the source, provide a link to the Creative Commons license, and indicate if changes were made. The Creative Commons Public Domain Dedication waiver (http://creativecommons.org/ publicdomain/zero/1.0/) applies to the data made available in this article, unless otherwise stated. 
Osteoblast studies are performed using various culture models, such as immortalized cell lines (e.g., MG-63 or SaOS-2), induced osteoblasts from pluripotent stem cells, and harvested primary osteoblasts $[4,5]$. The potential of in vitro cultured osteoblasts to maintain their phenotype and activity depends on the cell type used. In the case of primary osteoblasts, cell phenotype and potential depends on the age, site of isolation, donor gender and method of cell isolation and culture [5, 6]. The primary osteoblast culture could be obtained in the process of progressive enzymatic digestion of bone tissue [7] or cell migration from the bone explants [6]. Generally, using such a factor as ascorbic acid, $1 \alpha, 25$-dihydroxyvitamin $\mathrm{D}_{3}$ and dexamethasone, it is possible to induce osteogenesis of stem or progenitor cells, such as mesenchymal stem cells or induced pluripotent stem cells, or of osteoprogenitors and osteoblasts [5, 8-11]. In this study, we concentrated on the osteogenic potential of human bone-derived cells (HBDCs) obtained from bone explant enzymatic digestion and cultured in vitro.

Human osteogenic cells derived from various bone compartments are routinely established in short-term cultures. These cultures are heterogeneous and consist of different bone cell subpopulations. The subpopulations seem to be primary osteoprogenitor, premature and mature osteoblasts at various stages of differentiation [12]. Moreover, it was also described that in vitro HBDCs were able to differentiate into multiple mesenchymal lineages, suggesting their multipotent character $[13,14]$. Importantly, the primary osteoblast cultures provide more complex information about osteogensis, bone remodeling and regeneration than cell line cultures. The differences between primary osteoblasts and cell line cultures should be taken into account when studying processes of osteoblast differentiation in vitro. The growth and differentiation of HBDCs is regulated by growth factors, cytokines and hormones, and also depends on the cell density in culture [5]. In this study, we focused on the role of cell adhesion in HBDC differentiation.

Cell adhesion supports tissue morphogenesis integrity as well as tissue repair. Bone cell adhesion to the extracellular matrix directly regulates cell growth, the expression of the osteoblast phenotype and the process of bone tissue formation [15].

Integrins are the adhesion molecules involved in the process of cell adhesion. Integrin-mediated adhesion is a highly regulated process involving receptor-ligand interactions and cell spreading. Upon ligand binding, integrins rapidly associate with the actin cytoskeleton and cluster together to form focal contacts, which are complexes composed of structural and signaling molecules such as focal adhesion kinase (FAK).

Focal adhesions act as structural links between the cytoskeleton and extracellular matrix and mediate stable cell adhesion and migration [16]. The binding of transmembrane integrin adhesion receptors to ECM components, such as fibronectin and COLI, activates signaling pathways engaged in cell-cycle progression, gene expression, matrix mineralization and survival of primary osteoblasts [17]. Osteoprogenitor cells and osteoblasts express multiple integrins, including $\alpha 1 \beta 1, \alpha 2 \beta 1, \alpha 3 \beta 1, \alpha 4 \beta 1, \alpha 5 \beta 1, \alpha 8 \beta 1$ and $\alpha v \beta 3$, which bind to numerous ECM proteins [18]. Blocking adhesion with COLI-specific peptides or antibodies directed against the collagen-binding integrin $\alpha 2 \beta 1$ affects with the activity of Runx/Cbfa1 transcription factors, expression of osteoblast-specific genes, and matrix mineralization [19].

The purpose of this study was to characterize HBDC phenotypes by defining cell morphology changes and the proliferation and differentiation rate. We also analyzed actin cytoskeleton organization and adhesive protein expression. The phonotype of 
in vitro cell culture depends on the manipulation of the biological material and the culture conditions, including medium, time and the presence of compounds that influence cell proliferation and differentiation [20]. The primary focus of this study was HBDC biology in vitro as part of an evaluation of their tissue engineering potential.

\section{Methods}

The Local Ethics Committee of the Warsaw Medical University approved all procedures (Decision No. KB/74/2005). All of the donors provided informed consent.

\section{Primary culture of HBDCs}

Human bone-derived cells (HBDCs) were isolated from trabecular bone tissue chips harvested from the bottom distal part of the long tight bone during standard procedure knee joint alloplasty. Material from seven female patients ranging in age from 59 to 63 was used. Cells harvested from different donors were cultured separately. The procedure of HBDC isolation was based on the protocols described by Gallagher et al. [21] with modifications [22].

Briefly, the extracted bone pieces were purified from other tissues by scraping, and the bone was cut into $1-\mathrm{mm}$ pieces and washed with phosphate-buffered saline (PBS) containing $\mathrm{Ca}^{2+}$ and $\mathrm{Mg}^{2+}$ ions (Gibco BRL, Life Technologies B.V. Breda, The Netherlands),.), and subsequently digested overnight using a collagenase XI S (200 U $\mathrm{ml}^{-1}$; Sigma-Aldrich, St. Louis, USA).).

Next, samples were washed with PBS and placed in a $75-\mathrm{cm}^{3}$ cell culture flasks (CostarNunc), containing the standard culture medium: Dulbecco's modified Eagle's medium (DMEM; Gibco) supplemented with a $10 \%$ final concentration of heat-inactivated fetal

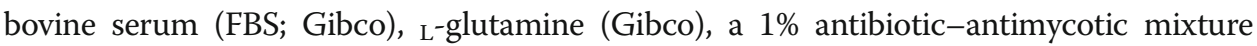
consisting of 10,000 $\mathrm{U}$ of penicillin (base), $10 \mathrm{mg}$ of streptomycin (base) and $25 \mu \mathrm{g}$ of amphotericin $\mathrm{B} \mathrm{ml}^{-1}$ (Gibco), and $100 \mathrm{mM}_{\mathrm{L}}$-ascorbic acid 2-phosphate hydrate sesquimagnesium salt (Sigma-Aldrich).

The explants were cultured in a $\mathrm{CO}_{2}$ incubator at $37{ }^{\circ} \mathrm{C}$ in $5 \% \mathrm{CO}_{2}$ and humidified atmosphere. The medium was changed every 7 days. Within 2-4 weeks, osteoblast migration from the bone explants was observed. Then the explants were placed in two or three different flasks to obtain two populations of cells originating from the same donor. After confluence, HBDCs were detached using collagenase and trypsin/EGTA (Gibco) treatment.

The cells from the first passage were used in all of the experiments. Cells were seeded in 24-well dishes at a density of $4 \times 10^{4}$ cells per well $\left(1.9 \mathrm{~cm}^{2}\right)$ in a differentiating medium containing $10 \mathrm{nM}$ dexametasone (Sigma-Aldrich) and $100 \mathrm{nM} \mathrm{1 \alpha ,25-dihydrix-}$ ycholecalciferol (Sigma-Aldrich) to induce osteogenesis. The morphology of the cells was analyzed using an inverted, phase-contrast microscope (Nikon Eclipse TE2000-u).

\section{Evaluation of cell proliferation and viability}

To evaluate cell proliferation, HBDCs were plated at a density of $4 \times 10^{4}$ cells per well in differentiating medium. The cell growth curve was assessed on the basis of cells number counted using a Burker's camera. Subsequently, the adherent cells were enzymatically detached from the surface of wells using $1 \mathrm{mM}$ EDTA and $0.25 \%$ trypsin and the cell number was determined in a counting chamber. 
An XTT (Sigma-Aldrich) assay was used to examine the viability of cells according to the manufacturer's protocol. Cell cultures were washed three times with PBS, and then XTT working solution was added and left for $4 \mathrm{~h}$ at $37^{\circ} \mathrm{C}$. The final product of the reaction was measured using a FLUOstar OPTIMA ELISA plate reader (BMG LABTECH $\mathrm{GmbH}$ ) at $450 \mathrm{~nm}$. The cell number and viability on days 1, 7, 14 and 21 of culture was determined. Seven independent experiments were performed. The data are presented as means \pm standard deviation. Student's $t$-test was used for statistical analysis to compare the results. $p<0.05$ was considered significant.

\section{Determination of alkaline phosphatase (ALP) activity}

The culture medium was removed and the wells were washed three times with PBS, and then lysed for $1 \mathrm{~h}$ at $4{ }^{\circ} \mathrm{C}$ with cell lysis buffer consisting of $10 \mathrm{mM}$ Tris- $\mathrm{HCl}$ (pH 7.5) and $0.1 \%$ Triton X-100 (Sigma). Then, $50 \mu$ of the lysates were assayed using p-nitrophenyl phosphate substrate (Sigma) according to the manufacturer's instructions. The colorimetric reaction was carried out at $37^{\circ} \mathrm{C}$ for $30 \mathrm{~min}$, then stopped using $3 \mathrm{M} \mathrm{NaOH}$ and EDTA solution. The absorbance of the reaction product was determined at $405 \mathrm{~nm}$ using the FLUOstar OPTIMA ELISA reader. The ALP activity (U/cell number) was measured on days 7, 14 and 21 . Seven independent experiments were performed. The data are presented as means \pm standard deviation. Student's $t$-test was used for statistical analysis to compare the results. $p<0.05$ was considered significant.

\section{Total protein content assay}

On days 7, 14 and 21 of culture, the total protein content was determined in the cell lysates using a Protein Assay BCA kit (Pierce Biotechnology, Inc., Rockford, USA). Test.). The test was done according to the manufacturer's protocol. Absorbance was measured at $562 \mathrm{~nm}$ and the total protein content was calculated. Seven independent experiments were performed. The data are presented as means \pm standard deviation. Student's $t$-test was used for statistical analysis to compare the results. $p<0.05$ was considered significant.

\section{Determination of collagen production}

The collagen assay is based on binding of Sirius red dye to the triple helical collagen fibril. On days 7, 14 and 21 of culture, the cells were washed three times with PBS, and then $0.1 \%$ Sirius red in saturated picric acid was added (Sigma-Aldrich), and incubated for $60 \mathrm{~min}$ at room temperature. Then the plates were rinsed three times with $10 \mathrm{mM}$ $\mathrm{HCl}$. The presence of collagen was observed under an inverted microscope (Nikon Eclipse TE2000-u). The collagen-binding stain was finally eluted with $0.1 \mathrm{M} \mathrm{NaOH}$ and absorbance was read at $540 \mathrm{~nm}$ using the FLUOstar OPTIMA ELISA reader. Seven independent experiments were performed. The data are presented as means \pm standard deviation. Student's $t$-test was used for statistical analysis to compare the results. $p<0.05$ was considered significant.

\section{Actin microfilaments staining}

HBDCs were plated at a density of $2 \times 10^{4}$ cells on a cover slide $\left(1.9 \mathrm{~cm}^{2}\right)$ in standard medium. The next day, the cells were treated with differentiating medium. On days 7 , 14 and 21 of culture, the attached cells were washed three times with PBS (Gibco), 
fixed in 3\% formaldehyde/PBS for $10 \mathrm{~min}$, and permeabilized in $0.1 \%$ Triton X-100/ PBS (Sigma) for $1 \mathrm{~min}$ at room temperature. The washing step was followed by incubation with TRITC-conjugated phalloidin (Sigma-Aldrich) diluted in PBS (1:200) for $40 \mathrm{~min}$, at room temperature. After a final wash in PBS, specimens were mounted in Ultra Cruz Mounting Medium containing DAPI (Santa Cruz Biotechnology, Santa Cruz, CA) and observed using a fluorescent microscope (Nikon Eclipse TE2000-u) connected to Nikon Digital Sight DS-U1 camera. Three independent experiments were performed and representative images are shown.

\section{Immunofluorescence localization of $\beta 1$ integrin subunit and FAK}

HBCS were seeded at a density of $2 \times 10^{4}$ cells on a cover slide in standard medium. The next day, they were treated with differentiating medium. On days 7, 14 and 21 of culture, the cells were washed in PBS and fixed with $3 \%$ formaldehyde in PBS (Gibco). Then, the cells were permeabilized in $0.1 \%$ Triton X-100 in PBS, washed three times in PBS and incubated in $0.25 \%$ glycine in PBS for $30 \mathrm{~min}$ at room temperature. Nonspecific binding was blocked with $3 \%$ bovine serum albumin (BSA, Sigma) diluted in PBS for $30 \mathrm{~min}$. Cells were incubated with primary antibody overnight at $4{ }^{\circ} \mathrm{C}$. Primary antibodies were mouse monoclonal anti- $\beta 1$ integrin (Santa Cruz Biotechnology) and mouse monoclonal anti-FAK (Santa Cruz Biotechnology). They were diluted 1:100 in $3 \%$ BSA/PBS. Then, the cells were washed in PBS and incubated with secondary biotin-conjugated antibodies (1:100 in 3\% BSA/PBS; Santa Cruz Biotechnology), followed by incubation with Extravidin-TRITC (1:100 in 3\% BSA/PBS; Sigma-Aldrich). Unlabeled cells and cells labeled with a secondary biotin-conjugated antibody and with extravidin-TRITC were used as a control.

After a final wash in PBS, specimens were mounted in Ultra Cruz Mounting Medium containing DAPI (Santa Cruz Biotechnology). Images of stained cells were captured using a fluorescent microscope (Nikon Eclipse TE2000-u) connected to Nicon Digital Sight DS-U1 camera. Three independent experiments were performed and representative images are shown.

\section{Semi-quantitative RT-PCR assay}

Total RNA was isolated from cells harvested on day 0, with the cells under nondifferentiating conditions in the standard medium, and on days 7, 14 and 21, with the cells cultured with differentiating medium, using a High Pure Isolation Kit (Roche Diagnostics U.S. Heagquarters, Indianapolis, USA).). Specific transcripts were amplified using semi-quantitative RT-PCR with $1 \mu \mathrm{g}$ of total RNA as a template and specific oligonucleotide primers, using a Titan One-Tube RT-PCR Kit (Roche Diagnostics), according to the manufacturer's instructions. The sequence of the oligonucleotides used in the RT-PCR was determined based on the literature review (Table 1). The oligonucleotides were synthesized by Singen Biotech Sp. z o.o, Wrocław, Poland.

The obtained cDNA fragments were separated on 2\% agarose LE gels (Roche Diagnostic). The gels were stained with ethidium bromide and the optical density (Odu) of bands was analyzed with Gel Doc 2000 software (Bio-Rad, Hercules, CA, USA). To evaluate the expression levels of transcripts in a semi-quantitative manner, the optical densities of the amplified cDNA fragments were compared with the average density 
Table 1 List of primers used in the RT-PCR analysis

\begin{tabular}{|c|c|c|}
\hline Target gene & Primer sequences & Fragment size (bp) \\
\hline ALP & $\begin{array}{l}\text { F 5'-ACGTGGCTAAGAATGTCATC-3' } \\
\text { R 5'-AGGGCTCCAACGAGATCGAGATCCG-3' }\end{array}$ & 475 \\
\hline COLI & $\begin{array}{l}\text { F 5'-AACTGAAAGCTGAATCCTTCCA-3' } \\
\text { R 5-'TGCCCAAGAAACAAAGCTTC-3' }\end{array}$ & 223 \\
\hline GAPDH & $\begin{array}{l}\text { F 5'-TCAAGGAAGCTACGGGCA-3' } \\
\text { R 5'-TGGCAGAAATTACACACACACAC-3' }\end{array}$ & 250 \\
\hline$\beta 1$ integrin subunit & $\begin{array}{l}\text { F 5-'AAGGGCGTGTTGGTAGACATT-3' } \\
\text { R 5'-TGACACATCTCACACGTTTGC-3' }\end{array}$ & 424 \\
\hline
\end{tabular}

of the housekeeping gene GAPDH. One representative result from each of three independent experiments is presented.

\section{Results}

The primary HBDC culture serves as a suitable model to study osteogenesis. For a comprehensive examination of HBDCs in vitro, the cells were cultured under conditions that allow osteoblast differentiation. The following parameters were evaluated: cell number and viability, total protein content, alkaline phosphatase activity, collagenous matrix production, expression of the osteogenic genes ALP and COLI, localization, and expression of the actin cytoskeleton and two proteins engaged in cell adhesion: $\beta 1$ integrin subunits and FAK.

The cultures obtained from bone explants of seven different patients were evaluated. The HBDCs were analyzed $24 \mathrm{~h}$ after cell seeding, i.e., during the adhesion phase, on day 7 of culture, i.e., during the proliferation stage, and on days 14 and 21 of culture, i.e., during the early and late maturation stages.

\section{Culture of HBDCs}

Morphological changes were observed to accurately characterize the primary human osteoblast culture (Fig. 1). Long and narrow fibroblast-like cells were observed during the adhesion (Fig. 1a) and proliferation stages (days 7 and 9, Fig. 1b, c). On days 14 and 17 of culture (Fig. 1d, e), the cell morphology had changed to a cuboidal shape. Finally, on day 21 of culture (Fig. 1f), the cells became elongated. Analysis of the proliferation curve and cell viability showed that HBDCs intensively proliferate during the first 7 days of culture (Fig. 2). Thereafter, as measured on days 14 and 21, the proliferation and cell viability increased at a lower rate (Fig. 2).

\section{Phenotypic characteristics of HBDCs}

To evaluate the osteoblast phenotype, we used semi-quantitative RT-PCR to investigate the gene expression of the osteoblast markers type I collagen (COLI) and alkaline phosphatase (ALP). Samples were obtained from primary human osteoblasts cultured in undifferentiating conditions (standard medium, point 0 ) and on days 7 , 14 and 21 of culture in differentiating medium. We compared the average density of the GAPDH mRNA band (set to 100\%) with the bands corresponding to COLI and ALP mRNAs (Fig. 3) and found that the highest level of mRNA encoding COLI was observed at point 0 , when HBDCs were growing in standard medium. On day 7 , it 

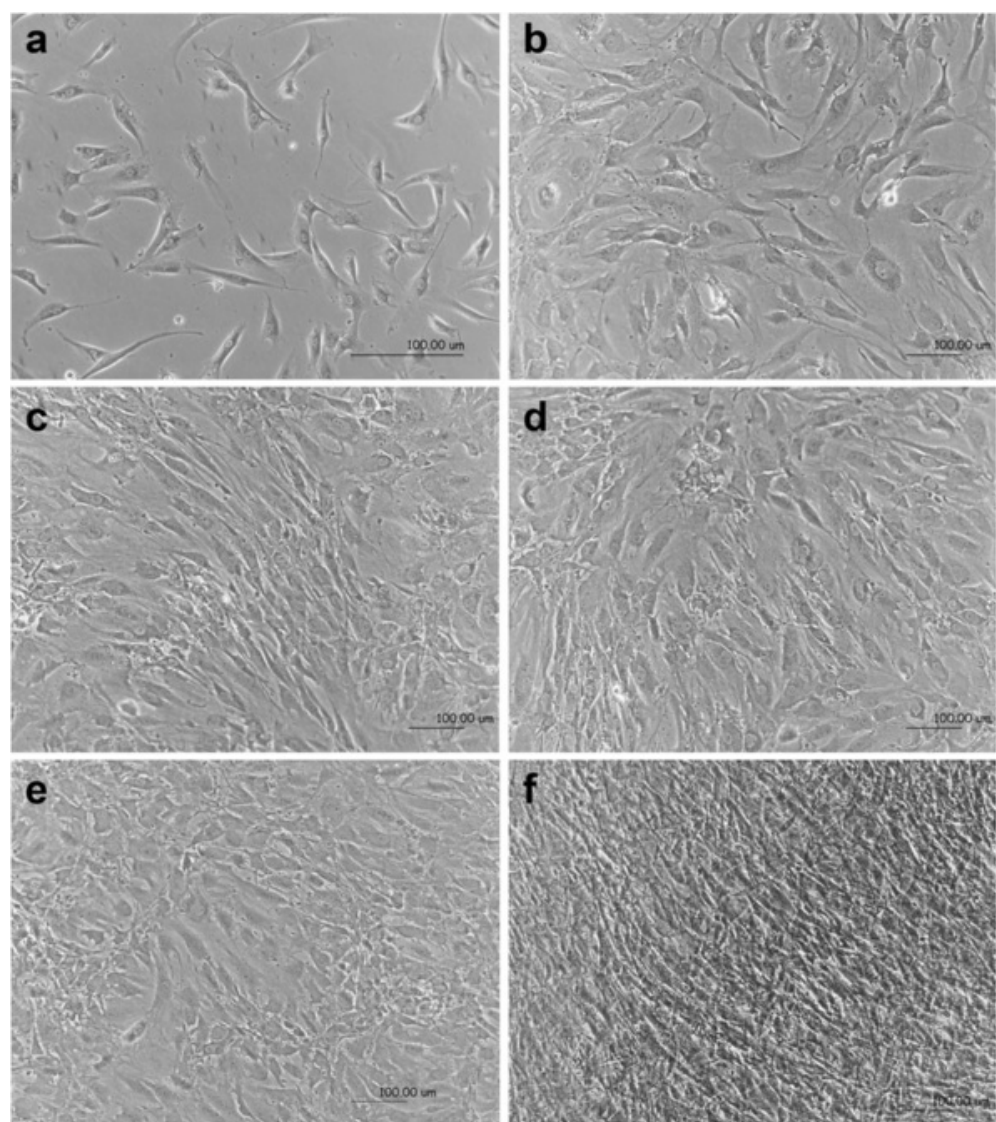

Fig. 1 Morphological changes of HBDCs during their in vitro differentiation. The cells were cultured in differentiating medium. Phase contrast images were taken $24 \mathrm{~h}$ after cell seeding (a), and on day 7 (b), 9 (c), 14 (d), 17 (e) and 21 (f) of culture. The morphology of HBDCs changed from a fibroblastic-like to a cuboidal shape. Seven independent experiments were performed and representative images are shown. Scale bar: $100 \mu \mathrm{m}$

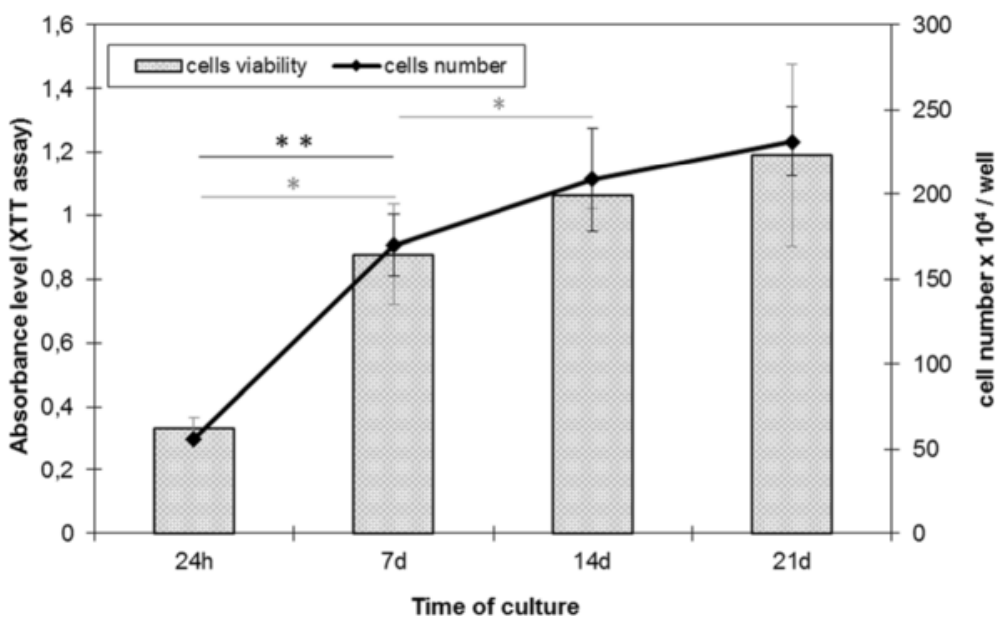

Fig. 2 The cell number and viability (XTT assay) $24 \mathrm{~h}$ after cell seeding, and on days 7, 14 and 21 of culture. The results of the XTT assay are presented as the absorbance level. It was determined as a linear relationship between cell number and viability. Seven independent experiments were performed. The data are presented as means \pm standard deviation. Cell number is in black; cell viability is in grey. Student's $t$-test was used for statistical analyses. ${ }^{*} p<0.05$ (considered significant) 


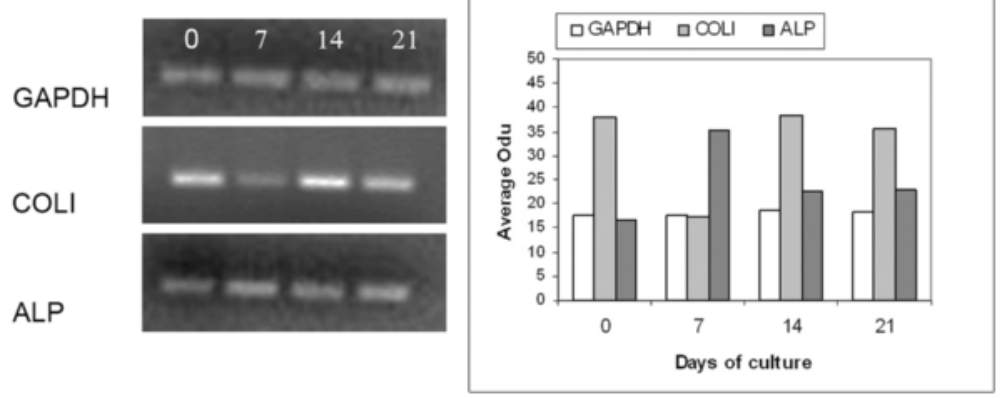

Fig. 3 Expression of osteoblast markers, i.e., type I collagen (COLI), alkaline phosphatase (ALP), osteocalcin (OC) determined using semi-quantitative RT-PCR. Analysis of the representative gels and the level of GAPDH, COLI, ALP and OC mRNA (the average optical density of bands; Odu) is presented in the charts $(n=3)$. Results are normalized to the housekeeping gene level (GAPDH). 0 - cell cultured under undifferentiating conditions in standard medium; 7, 14, 21 - cells cultured under osteogenic conditions in differentiating medium

was 2.2-fold lower. During osteogenic differentiation, the level of COLI mRNA increased again, and reached the same level as observed at point 0 on day 14, maintaining this level through day 21. During the differentiation of HBDCs the level of ALP mRNA was the highest on day 7, then decreased 1.6-fold and 1.5-fold by days 14 and 21 respectively. There was no difference in the ALP expression level between days 14 and 21 .

The differentiation of human osteoblasts is associated with an increase in total protein synthesis (Fig. 4a), constant production of collagen (Fig. 4b) and an increase in ALP activity (Fig. 4c). At all stages of HBDC differentiation, there was no major difference in collagen production by the cells (Fig. 4b). The results of these analyses precisely reflect those obtained via collagen staining, where all HBDCs in culture showed the presence of collagen (Fig. 5). By contrast, the ALP enzymatic activity increased significantly from day 14 until 21 (maturation stage; Fig. 4c).

\section{Changes in actin organization and adhesive proteins expression during HBDCs differentiation}

To answer the question of how cytoskeleton organization and adhesion proteins expression changed during HBDC differentiation, we analyzed FAK, $\beta 1$ integrin and actin localization in vitro. At first, we analyzed the expression of mRNA encoding $\beta 1$ integrin subunits (Fig. 6a). The level of the integrin $\beta 1$ subunit increased during cell differentiation, and its mRNA was the highest on day 14 of culture. The $\beta 1$ integrin subunit visualized with immunocytochemistry was expressed in undifferentiated adherent cells (Fig. 6b) and in differentiating HBDCs (Fig. 6c, d). The $\beta 1$ integrin subunit was distributed in the membrane and focal contacts (Fig. 6b-d). Moreover, differentiating HBDCs (day 21) formed numerous focal adhesion contacts, as shown via immunolocalization of FAK, i.e., kinase was engaged in their formation (Fig. 6e).

Actin filaments were stained with phalloidin-TRITC (Fig. $6 \mathrm{f}-\mathrm{h}$ ), and many stress fibers were clearly visible in the cells during proliferation (Fig. 6f, g). The actin filaments were also detected at maturation stage (Fig. 6h). By day 7 of culture, HBDCs had spread to form numerous actin stress fibers, observed as long, linear, welldefined filaments arranged in large bundles tending to run parallel to each other 

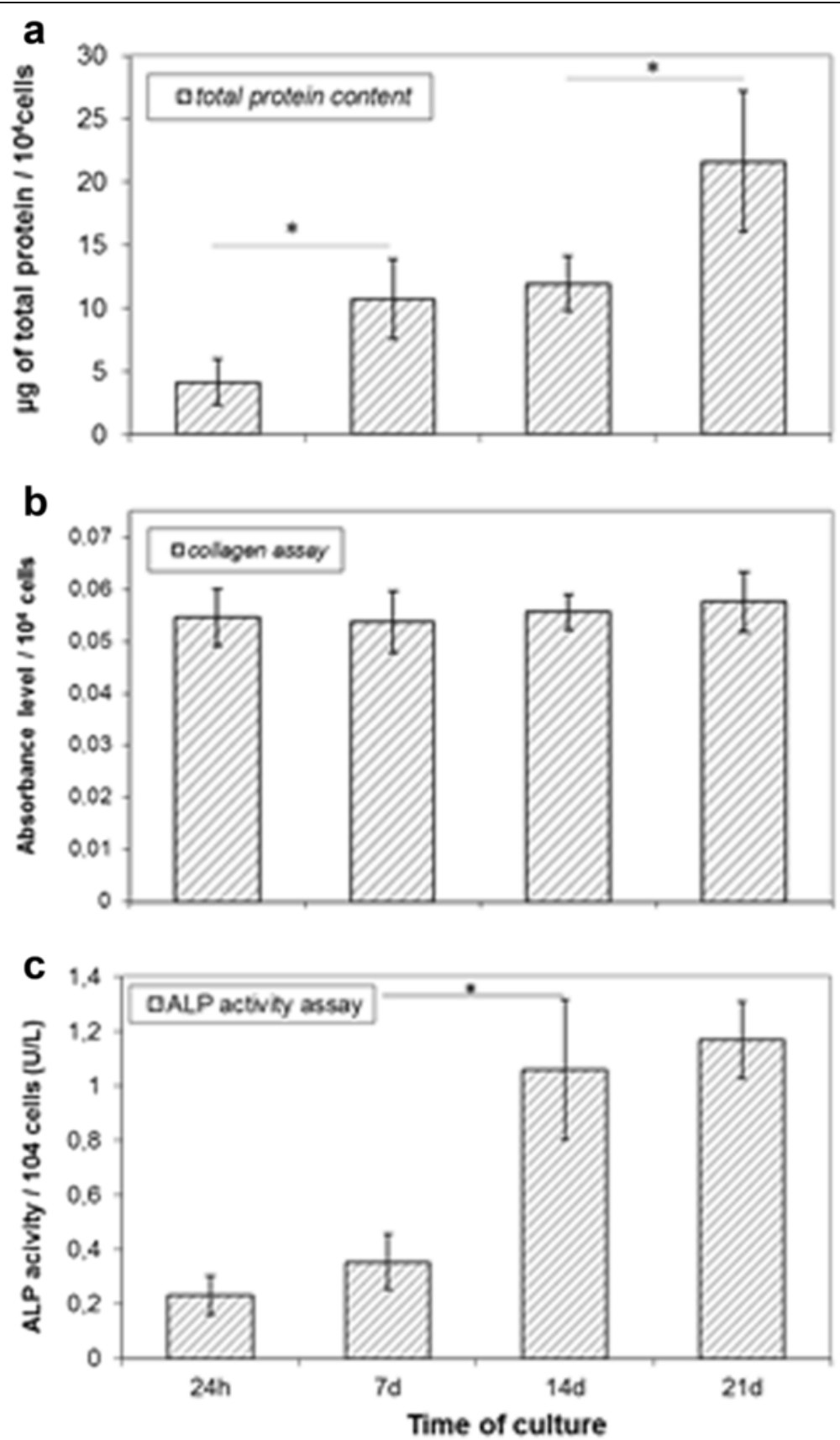

Fig. 4 The total protein content (a), collagen assay (b) and alkaline phosphatase (ALP) activity (c). The results of the collagen assay are presented as the absorbance level. The results from seven separate experiments are shown. The data are presented as means \pm standard deviation. Student's $t$-test was used for statistical analyses. ${ }^{*} p<0.05$ (considered significant)

(Fig. 6f). By day 14 of culture, the cell number had increased noticeably, with the cells having cuboidal shape and being substantially less spread. Actin cytoskeleton distribution had also started to change (Fig. 6g). In the last phase of osteoblast differentiation, the concentration of actin was the highest and a complex network of actin filaments was detected (Fig. 6h). Thus, differentiation of HBDCs accompanies reorganization of the actin cytoskeleton. 

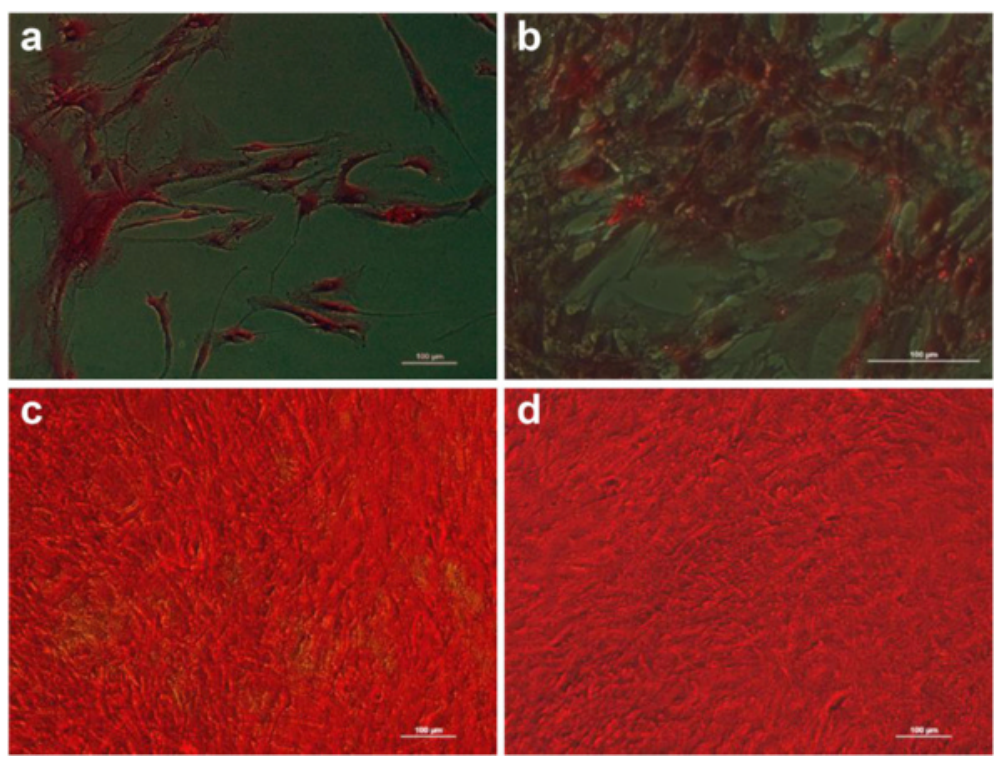

Fig. 5 Localization of collagen during differentiation of HBDCs on days 1 (a), 7 (b), 14 (c) and 21 (d). Three independent experiments were performed and representative images are shown. Scale bar: $100 \mu \mathrm{m}$

\section{Discussion}

Human osteogenic cells can be isolated from human bone and are able to differentiate and produce ECM proteins, which are the substrate for mineralization during bone formation. The aim of this study was to characterize the HBDC phenotype and investigate the osteoblast potential of these cells in vitro. Differentiation of HBDCs has been described as a three-step process consisting of the adhesion phase, proliferation phase and osteoblast maturation.

HBDCs are considered a source of cells for a therapy. The characteristics of these phases at molecular level are very important when considering using autologous bone transplants for human bone reconstruction. Isolated osteoblast cells prepared for implantation could be differentiated in vitro [23]. To induce differentiation of isolated HBDCs, a differentiating medium containing vitamin $\mathrm{C}$, vitamin D3 and dexamethasone was used. The role of vitamin C is to stimulate the synthesis of COLI [24]. Dexamethasone is a synthetic glucocorticosteroid that inhibits proliferation and induces differentiation of progenitor cells to osteoblast phenotype [25]. Vitamin D3 and dexamethasone regulate the differentiation of osteoblasts affecting the level of ALP expression and activity [26].

In this study, we used HBDCs from the first passage. As shown by Coelho et al., serial cell passages affect the number of cells and lead to a loss of the osteoblast phenotype [27]. It was noticed that the proliferation and viability of HBDCs first increased and then gradually stopped, starting from day 14 of culture, i.e., when the cells began to differentiate.

Markers such as ALP and COLI were monitored to assess the osteoblast potential of isolated HBDCs. The level of ALP mRNAs is one of the crucial factors to determine osteoblast differentiation. It is known that the expression of ALP mRNA is present in the early stages of osteoblast differentiation, increasing in mature osteoblasts and decreasing when osteoblasts differentiate to osteocytes [28]. Our results showed that ALP mRNA was detected in undifferentiated HBDCs, increased at the proliferation stage and slightly decreased during cell maturation. The time course of ALP gene expression 


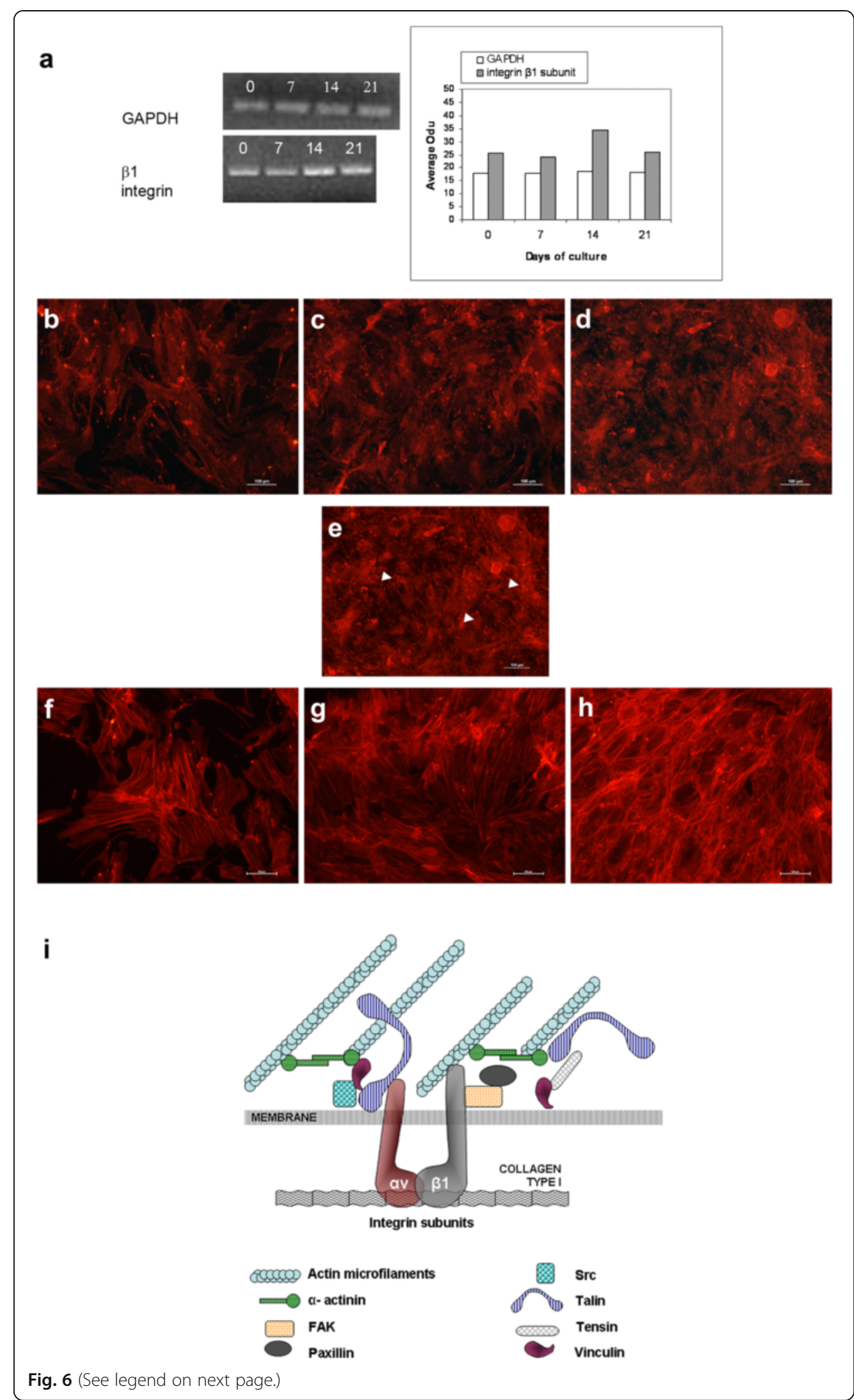


(See figure on previous page.)

Fig. 6 Changes in the expression levels and localization of the $\beta 1$ integrin subunit during differentiation of HBDCs. a Analysis of representative gels. The levels of GAPDH and $\beta 1$ integrin subunit mRNA are shown in the charts. Results are normalized to the level of the housekeeping gene (GAPDH). 0 - cell cultured under undifferentiating conditions in standard medium; 7, 14, 21 - cells cultured under osteogenic conditions in differentiating medium. b, c, d Immunolocalization of the $\beta 1$ integrin subunit on days 7 (b), 14 (c) and 21 (d) of HBDC differentiation. Three independent experiments were performed and representative images are shown. Scale bar: $100 \mu \mathrm{m}$. e Immunofluorescence staining for osteoblasts terminating in focal adhesion contacts as shown by FAK localization (on day 21 of HBDC culture). Focal adhesion plaques indicated by a white arrowhead. Three independent experiments were performed and representative images are shown. Scale bar: $100 \mu \mathrm{m}$. $\mathbf{f}-\mathbf{h}$ Localization of actin in differentiating HBDCs on days 7 (f), 14 (g) and 21 (h) of culture. Three independent experiments were performed and representative images are shown. Scale bar: $100 \mu \mathrm{m}$. i Cell adhesion to ECM proteins is mediated through integrin receptors, which are clustered within adhesive cellular structures known as focal adhesion or focal contact plaques. Focal adhesion plaques are supramolecular assemblies containing structural (talin, vinculin, tensin, actin filaments) and signaling components (FAK, Src, paxilin) regulating cell functions via integrins

roughly fits with the increase in ALP activity as shown using an osteosarcoma cell line [29]. The increase in ALP activity correlates with the formation of bone-like structures in vitro [30]. Our study showed that ALP activity was detectable $24 \mathrm{~h}$ after cell seeding and increased during human osteoblast maturation.

The expression level of osteogenic markers varied depending on the donors, but the trends were the same. The extracellular matrix of the bone is composed of $90 \%$ collagenic proteins (type I collagen 97\%, type V collagen 3\%) and 10\% non-collagenic proteins (osteocalcin 20\%, osteonectin $20 \%$, bone sialoproteins $12 \%$, proteoglycans $10 \%$, osteopontin, fibronectin, bone morphogenic proteins, etc.). All these proteins are synthesized by osteoblasts and most are involved in cell adhesion. Fibrillar COLI, the predominant organic matrix composite in bone, functions as a three-dimensional template to control the spatial aspect of mineralization. The covalent intermolecular cross-links are the final collagen post-translation modification crucial for the stability of the fibrils. $1,25(\mathrm{OH})_{2} \mathrm{D}_{3}$ regulates collagen post-translational modifications and maturation in osteoblast cell culture [31].

We demonstrated that isolated and cultured HBDCs changed their morphology and that the expression and activity of ALP increased. Thus, the cells were able to differentiate in vitro into osteoblasts. However, the level of COLI mRNA and protein, the major component of ECM in bone tissue, did not differ significantly during HBDC differentiation. Nevertheless, as shown previously, the expression of osteocalcin also increased during differentiation of HBDCs cultured under the same conditions [28].

Bone cell differentiation from the undifferentiated state into functional active osteoblasts is a series of steps involving numerous proteins expressed at each stage [32, 33]. Cell adhesion to the substrate is the first phase of the reaction between cells and the extracellular substrate determining the morphology, proliferation and differentiation ability of cells. The oval HBDCs adhere to the surface of a culture dish and change into an elongated shape. This process was connected with reorganization of actin filaments and the formation of focal contacts. The architecture of the actin cytoskeleton is essential to maintain cell shape and signaling leading to proliferation or differentiation in vitro [34]. Also, inhibition of cell proliferation and induction (initiation) of cell differentiation was observed. During this process, HBDCs change shape, actin cytoskeleton reorganization is noticeable and there are an increased number of focal contacts containing FAK and the integrin $\beta 1$ subunit. 
It was previously shown that the $\alpha \mathrm{v}$ integrin subunit played an important role in the differentiation of human osteogenic cells [35]. In this study, we focused on other proteins engaged in the formation of focal contacts, i.e., $\beta 1$ integrin subunits and FAK. Focal contacts are the sites of adhesion between cultured cells and extracellular proteins. Membrane receptors such as integrins play a key role in the formation of focal contacts and link extracellular proteins with the actin cytoskeleton. Numerous proteins like talin, paxillin and vinculin are known to mediate interactions between actin filaments and integrins [36]. Via numerous signaling molecules, integrins connect to the actin cytoskeleton and mediate transduction of signals from the extracellular matrix to the cell nucleus [37]. All bone cell types expressed $\alpha 1$ and $\alpha 5$ subunits, whereas a subpopulation of osteoblast cells expressed $\alpha 2, \alpha v$ and $\beta 1$ integrin subunits [38]. Human osteoblasts cultured in vitro expressed a high level of $\alpha 1 \beta 1, \alpha 3 \beta 1, \alpha 5 \beta 1$ and $\alpha v \beta 5$ and much lower levels of $\alpha 2 \beta 1, \alpha 4 \beta 1, \alpha v \beta 1$ and $\alpha v \beta 3$ integrins.

The main receptor mediating adhesion between osteoblasts and extracellular matrix proteins is the $\beta 1$ integrin subunit [39]. $\beta 1$ integrin directly binds a number of structural and regulatory proteins of focal contacts, such as talin [40] and FAK [41]. It was shown that human osteoblasts cultured on substrates containing tripeptide RGD (Arg-Gly-Asp) express the $\alpha v$ and $\beta 1$ integrin subunits [42]. The RGD motif that is present in several bone matrix proteins is a ligand for integrins and stimulates osteoblast adhesion to the substrate [43]. We previously showed that $\alpha \mathrm{v}$ integrin subunit expression significantly increases during HBDC differentiation into osteoblasts [35]. In this study, we demonstrated that expression of the $\beta 1$ integrin subunit increases during HBDC differentiation. Moreover, both proteins, i.e., the $\alpha \mathrm{v}$ [35] and $\beta 1$ integrin subunits, were localized in numerous focal contacts formed during HBDC differentiation.

\section{Conclusions}

HBDC differentiation is associated with changes in cell shape, the production of collagen and an increase in ALP activity, as well as with the reorganization of actin cytoskeleton and an increased number of focal contacts containing FAK and the integrin $\beta 1$ subunit. An increase in integrin $\beta 1$ subunit mRNA expression was also recorded. Thus, we suggest that integrin $\alpha v$ [35] and $\beta 1$ can be considered as markers of osteogenic differentiation. Moreover, the $\alpha v$ and $\beta 1$ integrin subunits may be suitable new candidates to evaluate the differentiation of primary human osteoblasts in culture.

\section{Abbreviations}

ALP: Alkaline phosphatase; BSP: Bone sialoprotein; COLI: Collagen type I; ECM: Extracellular matrix proteins; FAK: Focal adhesion kinase; FBS: Fetal bovine serum; HBDCs: Human bone-derived cells; OC: Osteocalcin; ON: Osteonectin; OP: Osteopontin

\section{Acknowledgments}

Special thanks to Professor Małgorzata Lewandowska-Szumieł for her advice and support during the planning phase of these studies.

Funding

This work was supported in part by research grant no. N N302157037 from the Polish funds for scientific research in 2009-2012 (principal investigator Professor Małgorzata Witkowska-Zimny), and grant no. 3 T08A 00130 from the Polish Ministry of Science and Higher Education (principal investigator Edyta Wróbel). 


\section{Authors' contributions}

EW participated in the design of the study, cell cultures, molecular studies, immunocytochemistry, biochemistry analysis and preparation of the manuscript. JL carried out cell cultures, molecular studies, immunocytochemistry, biochemistry analysis and analysis of the results. EB participated in analysis of the results and helped to draft the manuscript. All authors read and approved the final manuscript.

\section{Competing interests}

The authors declare that they have no competing interests.

\section{Ethics approval and consent to participate}

The Local Ethics Committee of the Warsaw Medical University approved all procedures (Decision No. KB/74/2005). All the donors provided informed consent.

\section{Author details}

${ }^{1}$ Department of Biophysics and Human Physiology, Faculty of Health Sciences, Medical University of Warsaw, ul. Chalubinskiego 5, 02-004, Warsaw, Poland. '2Department of Cytology, Institute of Zoology, Faculty of Biology, University of Warsaw, ul. Miecznikowa 1, 02-096, Warsaw, Poland.

\section{Received: 2 July 2016 Accepted: 28 October 2016}

\section{Published online: 16 November 2016}

\section{References}

1. Owen TA, Aronow M, Shalhoub V, Barone LM, Wilming L, Tassinari MS, Kennedy MB, Pockwinse S, Lian JB, Stein GS. Progressive development of the rat osteoblast phenotype in vitro: reciprocal relationships in expression of genes associated with osteoblast proliferation and differentiation during formation of the bone extracellular matrix. J Cell Physiol. 1990;143:420-30.

2. Igarashi M, Kamiya N, Hasegawa M, Kasuya T, Takahashi T, Takagi M. Inductive effects of dexamethasone on the gene expression of Cbfa1, Osterix and bone matrix proteins during differentiation of cultured primary rat osteoblasts. J Mol Histol. 2004;35:3-10.

3. Gerstenfeld LC, Chipman SD, Kelly CM, Hodgens KJ, Lee DD, Landis WJ. Collagen expression, ultrastructural assembly, and mineralization in cultures of chicken embryo osteoblasts. J Cell Biol. 1988;106:979-89.

4. Kartsogiannis V, Ng KW. Cell lines and primary cell cultures in the study of bone cell biology. Mol Cell Endocrinol. 2004;228:79-102.

5. Czekanska EM, Stoddart MJ, Richards RG, Hayes JS. In search of an osteoblast cell model for in vitro research. Eur Cell Mater. 2012;24:1-17.

6. Di Silvio L, Gurav N. Osteoblasts. Human cell culture: primary mesenchymal cells. Kluwer Academic Publishers. 2001;5:221-41

7. Peck WA, Binge SJ, Fedack SA. Bone cells: biochemical and biological studies after enzymatic isolation. Science. 1964;146:1476-7.

8. Gallagher JA. Human osteoblast culture. Methods Mol Med. 2003;80:3-18.

9. Kabiri M, Kul B, Lott WB, Futrega K, Ghanavi P, Upton Z, Doran MR. 3D mesenchymal stem/stromal cell osteogenesis and autocrine signalling. Biochem Biophys Res Commun. 2012;419:142-7.

10. Park BW, Kang EJ, Byun JH, Son MG, Kim HJ, Hah YS, Kim TH, Mohana Kumar B, Ock SA, Rho GJ. In vitro and in vivo osteogenesis of human mesenchymal stem cells derived from skin, bone marrow and dental follicle tissues. Differentiation. 2012;83:249-59.

11. Witkowska-Zimny M, Walenko K, Wrobel E, Mrowka P, Mikulska A, Przybylski J. Effect of substrate stiffness on the osteogenic differentiation of bone marrow stem cells and bone-derived cells. Cell Biol Int. 2013;37:608-16.

12. Thavarajah M, Evans DB, Kanis JA. Differentiation of heterogeneous phenotypes in human osteoblast cultures in response to 1,25-dihydroxyvitamin D3. Bone. 1993;14:763-7.

13. Kassem M, Abdallah BM, Saeed H. Osteoblast cells: differentiation and trans-differentiation. Arch Biochem Biophys. 2008;473:183-7.

14. Noth U, Osyczka AM, Tuli R, Hickok NJ, Danielson KG, Tuan RS. Multilineage mesenchymal differentiation potential of human trabecular bone-derived cells. J Orthop Res. 2002;20:1060-9.

15. Athanassiou G, Deligianni D. Adhesion strength of individual human bone marrow cells to fibronectin. Integrin beta1-mediated adhesion. J Mater Sci Mater Med. 2001;12:965-70.

16. Sastry SK, Burridge K. Focal adhesions: a nexus for intracellular signaling and cytoskeletal dynamics. Exp Cell Res. 2000;261:25-36.

17. Garcia AJ, Reyes CD. Bio-adhesive surfaces to promote osteoblast differentiation and bone formation. J Dent Res. 2005;84:407-13.

18. Moursi AM, Globus RK, Damsky CH. Interactions between integrin receptors and fibronectin are required for calvarial osteoblast differentiation in vitro. J Cell Sci. 1997;110:2187-96.

19. Xiao G, Wang D, Benson MD, Karsenty G, Franceschi RT. Role of the alpha2-integrin in osteoblast-specific gene expression and activation of the Osf2 transcription factor. J Biol Chem. 1998;273:32988-94.

20. Chavassieux PM, Chenu C, Valentin-Opran A, Merle B, Delmas PD, Hartmann DJ, Saez S, Meunier PJ. Influence of experimental conditions on osteoblast activity in human primary bone cell cultures. J Bone Miner Res. 1990;5:337-43.

21. Gallagher JA, Gundle R, Beresford JN. Isolation and culture of bone-forming cells (osteoblasts) from human bone. Methods Mol Med. 1996;2:233-62.

22. Kudelska-Mazur D, Lewandowska-Szumiel M, Mazur M, Komender J. Osteogenic cell contact with biomaterials influences phenotype expression. Cell Tissue Bank. 2005;6:55-64.

23. Gao J, Dennis JE, Muzic RF, Lundberg M, Caplan Al. The dynamic in vivo distribution of bone marrow-derived mesenchymal stem cells after infusion. Cells Tissues Organs. 2001;169:12-20. 
24. Chan D, Lamande SR, Cole WG, Bateman JF. Regulation of procollagen synthesis and processing during ascorbate-induced extracellular matrix accumulation in vitro. Biochem J. 1990;269:175-81.

25. Cheng SL, Yang JW, Rifas L, Zhang SF, Avioli LV. Differentiation of human bone marrow osteogenic stromal cells in vitro: induction of the osteoblast phenotype by dexamethasone. Endocrinology. 1994;134:277-86.

26. Mori K, Shioi A, Jono S, Nishizawa Y, Morii H. Dexamethasone enhances In vitro vascular calcification by promoting osteoblast differentiation of vascular smooth muscle cells. Arterioscler Thromb Vasc Biol. 1999:19:2112-8.

27. Coelho MJ, Cabral AT, Fernande MH. Human bone cell cultures in biocompatibility testing. Part I: osteoblast differentiation of serially passaged human bone marrow cell cultured in alpha-MEM and in DMEM. Biomaterials. 2000;21:1087-94

28. Weinreb M, Shinar D, Rodan GA. Different pattern of alkaline phosphatase, osteopontin, and osteocalcin expression in developing rat bone visualized by in situ hybridization. J Bone Miner Res. 1990;5:831-42.

29. Murray E, Provvedini D, Curran D, Catherwood B, Sussman H, Manolagas S. Characterization of a human osteoblast osteosarcoma cell line (SAOS-2) with high bone alkaline phosphatase activity. J Bone Miner Res. 1987;2:231-8.

30. Rosa AL, Beloti MM. Development of the osteoblast phenotype of serial cell subcultures from human bone marrow. Braz Dent J. 2005;16:225-30.

31. Nagaoka H, Mochida Y, Atsawasuwan P, Kaku M, Kondoh T, Yamauchi M. 1,25(OH)2D3 regulates collagen quality in an osteoblast cell culture system. Biochem Biophys Res Commun. 2008;377:674-8.

32. Nakahara H, Goldberg VM, Caplan Al. Culture-expanded human periosteal-derived cells exhibit osteochondral potential in vivo. J Orthop Res. 1991;9:465-76.

33. Ng AM, Saim AB, Tan KK, Tan GH, Mokhtar SA, Rose IM, Othman F, Idrus RB. Comparison of bioengineered human bone construct from four sources of osteogenic cells. J Orthop Sci. 2005;10:192-9.

34. Zigmond SH. Signal transduction and actin filament organization. Curr Opin Cell Biol. 1996;8:66-73.

35. Wrobel E, Witkowska-Zimny M, Mrówka P, Głodkowska-Mrówka E. Integrin a $\lambda \pi n a$ v signaling influences phenotype and maturation of primary human osteoblasts on alumina surface. Engi Miomaterials. 2014;127:33-9.

36. Burridge K, Fath K. Focal contacts: transmembrane links between the extracellular matrix and the cytoskeleton. Bioessays. 1989;10:104-8.

37. Tuckwell DS, Reid KB, Barnes MJ, Humphries MJ. The A-domain of integrin alpha 2 binds specifically to a range of collagens but is not a general receptor for the collagenous motif. Eur J Biochem. 1996;241:732-9.

38. Hughes DE, Salter DM, Dedhar S, Simpson R. Integrin expression in human bone. J Bone Miner Res. 1993;8:527-33.

39. Nakayamada S, Okada Y, Saito K, Tamura M, Tanaka Y. Beta1 integrin/focal adhesion kinase-mediated signaling induces intercellular adhesion molecule 1 and receptor activator of nuclear factor kappaB ligand on osteoblasts and osteoclast maturation. J Biol Chem. 2003;278:45368-74.

40. Howe A, Aplin AE, Alahari SK, Juliano RL. Integrin signaling and cell growth control. Curr Opin Cell Biol. 1998;10:220-31.

41. Schaller MD, Parsons JT. pp125FAK-dependent tyrosine phosphorylation of paxillin creates a high-affinity binding site for Crk. Mol Cell Biol. 1995;15:2635-45.

42. Rezania A, Healy KE. Integrin subunits responsible for adhesion of human osteoblast-like cells to biomimetic peptide surfaces. J Orthop Res. 1999;17:615-23.

43. Haier J, Goldmann U, Hotz B, Runkel N, Keilholz U. Inhibition of tumor progression and neoangiogenesis using cyclic RGD-peptides in a chemically induced colon carcinoma in rats. Clin Exp Metastasis. 2002;19:665-72.

\section{Submit your next manuscript to BioMed Central and we will help you at every step:}

- We accept pre-submission inquiries

- Our selector tool helps you to find the most relevant journal

- We provide round the clock customer support

- Convenient online submission

- Thorough peer review

- Inclusion in PubMed and all major indexing services

- Maximum visibility for your research

Submit your manuscript at www.biomedcentral.com/submit 